PAPER

\title{
Comparison of intra-arterial thrombolysis with conventional treatment in patients with acute central retinal artery occlusion
}

\author{
M Arnold, U Koerner, L Remonda, K Nedeltchev, H P Mattle, G Schroth, M Sturzenegger, J Weber, \\ F Koerner
}

See Editorial Commentary, page 160

J Neurol Neurosurg Psychiatry 2005;76:196-199. doi: 10.1136/jnnp.2004.037135

See end of article for
authors' affiliations
$\ldots \ldots \ldots \ldots \ldots \ldots \ldots \ldots . \ldots . \ldots . .$.
Correspondence to:
Dr H Mattle, Department of
Neurology, University of
Berne, Freiburgstrasse,
Inselspital, CH-3010
Berne, Switzerland;
heinrich.mattle@insel.ch
Received 19 January 2004
In revised form
27 April 2004
Accepted 4 May 2004
Background: Several case series and a recent meta-analysis indicate that intra-arterial thrombolysis (IAT) is effective for the treatment of acute central retinal artery occlusion (CRAO).

Methods: A total of 37 patients with acute monocular blindness because of unilateral thromboembolic CRAO were treated with IAT using urokinase within six hours of the onset of symptoms. Visual outcome was compared with a control group of 19 patients, also seen within six hours, who did not undergo thrombolytic treatment. In both groups some patients were treated by paracentesis and/or acetazolamide. Predictors of visual outcome were evaluated.

Results: Visual improvement was more likely with IAT $(p=0.01)$ as were the chances to regain visual acuity of $>0.6$ significantly better $(p=0.04): 8 / 37$ patients $(22 \%)$ regained visual acuity of $>0.6$ in the IAT group and none (0/19) in the control group. Younger patients were more likely to regain some vision with $(p=0.012)$ or without IAT $(p=0.026)$. Three patients had minor treatment related cerebral ischaemic events, two had transient ischaemic attacks and one a minor stroke. There were no haemorrhagic complications.

Conclusions: This series of patients with CRAO demonstrated that IAT enhanced the chances of visual improvement compared with conventional treatment only. Furthermore, younger patients have a better chance to achieve some visual recovery.
A cute central retinal artery occlusion (CRAO) clinically manifests as painless monocular reduction of vision that remains poor most of the time. Efficacy regarding visual outcome of conventional treatments including paracentesis of the anterior chamber, acetazolamide, eyeball massage, heparin, and aspirin has not been clearly proved. ${ }^{12}$ However, several case series and a recent meta-analysis indicate that intra-arterial thrombolysis (IAT) may improve visual outcome in patients with CRAO. ${ }^{3-6}$ Potential side effects of IAT include haemorrhagic or ischaemic complications due to arteriography or the thrombolytic agents. For this reason, and because the benefit of IAT has not generally been widely reported, the optimal therapeutic approach in CRAO is still a matter of debate.

In 1998 we published our findings of a small series of patients with CRAO who had been treated with IAT and compared their visual outcome with historical controls. ${ }^{7}$ Since then we have included more patients in both the groups: those who received IAT and those who did not. In the present study we attempted to identify demographic and clinical predictors of visual outcome in these larger cohorts.

\section{SUBJECTS AND METHODS}

\section{Study design}

This is a retrospective case-control study. The findings from patients treated before 1998 were published previously (17 treated with IAT and 15 controls). ${ }^{7}$ Since then data of all consecutive patients with CRAO who came to our attention and fulfilled the selection criteria were added to the already existing data and the patients treated with IAT were compared with the patients treated conventionally.

\section{Patient selection}

Patients with thromboembolic CRAO presenting to our hospital within six hours of acute reduction in vision were included in this study. A staff ophthalmologist diagnosed the CRAO. Patients who had branch occlusions, vasculitis, arteriovenous malformations, or blood dyscrasias were excluded.

Between January 1990 and March 2003 we identified 56 patients with acute thromboembolic CRAO, seen within six hours of the onset of symptoms. IAT using urokinase was performed if (a) an ophthalmologist established clinical diagnosis of CRAO; $(b)$ a computed tomography (CT) scan excluded intracranial haemorrhage; $(c)$ arteriographic access to the ophthalmic artery was possible; $(d)$ the expected interval from onset of symptoms to IAT was less than six hours; (e) there were no individual clinical or laboratory based contraindications for thrombolysis; and $(f)$ the patient gave informed consent after the potential risks and benefits of the procedure were explained. The first IAT for CRAO was performed in 1993 and 37 patients underwent the procedure.

The remaining 19 patients with CRAO also seen within six hours of the onset of symptoms did not undergo thrombolytic treatment for the following reasons: $(a)$ the CRAO occurred befored IAT was available at our institution $(\mathrm{n}=5) ;(b)$ no experienced interventional neuroradiologist was on call or the team of neuroradiologists were engaged in another interventional procedure $(\mathrm{n}=11)$; (c) high grade carotid stenosis or occlusion prevented low risk access with the arteriography catheter into the ophthalmic artery $(n=3)$.

The causes of CRAO were classified into cardioembolic, large artery disease or other causes according to the Trial of Org 10172 in Acute Stroke Treatment (TOAST) criteria. ${ }^{8}$ All patients, who did not fulfil the TOAST criteria were classified as local thrombotic.

Abbreviations: CRAO, central retinal artery occlusion; IAT, intraarterial thrombolysis; TIA, transient ischaemic attack 
Table 1 Demographic and clinical characteristics of the thrombolysis and control groups

\begin{tabular}{|c|c|c|c|}
\hline \multirow[b]{2}{*}{ Characteristics } & \multicolumn{2}{|l|}{ Group } & \multirow[b]{2}{*}{ p value } \\
\hline & Thrombolysis & Controls & \\
\hline No. of patients & 37 & 19 & \\
\hline Mean (SD) age, years & $\begin{array}{l}63.4(14.6) \\
\text { (range } 23 \text { to } 83 \text { ) }\end{array}$ & $\begin{array}{l}62.8(13.0) \\
\text { (range } 39 \text { to } 81)\end{array}$ & NS \\
\hline \multicolumn{4}{|c|}{ 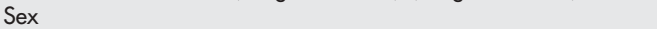 } \\
\hline Male & $22(59 \%)$ & $11(58 \%)$ & NS \\
\hline Female & $15(41 \%)$ & $8(42 \%)$ & \\
\hline \multicolumn{4}{|l|}{ Diabetes } \\
\hline Yes & $2(5 \%)$ & $1(5 \%)$ & NS \\
\hline No & $35(95 \%)$ & $18(95 \%)$ & \\
\hline \multicolumn{4}{|l|}{ Smoking } \\
\hline Yes & $4(11 \%)$ & $1(4 \%)$ & NS \\
\hline No & $33(89 \%)$ & $18(95 \%)$ & \\
\hline \multicolumn{4}{|c|}{ Hypercholesterolemia } \\
\hline Yes & $7(19 \%)$ & $3(16 \%)$ & NS \\
\hline No & $30(81 \%)$ & $16(84 \%)$ & \\
\hline \multicolumn{4}{|l|}{ Hypertension } \\
\hline Yes & $12(33 \%)$ & $7(37 \%)$ & NS \\
\hline No & $25(67 \%)$ & $12(63 \%)$ & \\
\hline \multicolumn{4}{|c|}{ Visual acuity on admission } \\
\hline Mean & 0.006 & 0.008 & NS \\
\hline$<0.01$ & $21(57 \%)$ & $8(42 \%)$ & \\
\hline $0.01-0.05$ & $16(43 \%)$ & 11 (58\%) & \\
\hline$>0.05$ & $0(0 \%)$ & $0(0 \%)$ & \\
\hline \multicolumn{4}{|c|}{ Time to treatment (minutes) } \\
\hline Median & 240 & 240 & NS \\
\hline Mean (SD) & $240(62)$ & $221(53)$ & \\
\hline \multicolumn{4}{|c|}{ Previous cerebrovascular or retinal event } \\
\hline Yes & $3(8 \%)$ & $1(5 \%)$ & NS \\
\hline No & $34(92 \%)$ & $18(95 \%)$ & \\
\hline \multicolumn{4}{|l|}{ Aetiology of CRAO } \\
\hline Carotid stenosis & $1(3 \%)$ & $3(16 \%)$ & NS \\
\hline Cardioembolic & $9(24 \%)$ & $4(21 \%)$ & \\
\hline Local thrombotic & $27(73 \%)$ & $12(63 \%)$ & \\
\hline $\begin{array}{l}\text { * } p \text {, difference between } \\
\text { Spearman's rank corre } \\
\text { CRAO, central retinal }\end{array}$ & $\begin{array}{l}\text { subgroups by Man } \\
\text { lation test. } \\
\text { artery occlusion; NS }\end{array}$ & $\begin{array}{l}\text { nn-Whitney } U \text { test } \\
\text { IS, not significant. }\end{array}$ & \\
\hline
\end{tabular}

\section{Thrombolysis group}

Clinical and demographic characteristics of the 37 patients in the thrombolysis group are summarised in table 1 . In all patients four vessel angiography, which takes normally about 10 minutes with biplane high resolution dedicated neurointerventional angiography equipment, was performed to assess the status of all cerebral vessels. Then the microcatheter tip (Fast Tracker 18; Target Therapeutics) was placed in the proximal segment of the ophthalmic artery under biplane road map control. Urokinase, in a dose ranging from 100000 units to 1000000 units (mean dose 677000 units) was injected manually through the microcatheter over 1090 minutes. Twenty one patients, most of whom were treated before the publication of the results of the International Stroke Trial received intravenous heparin in a therapeutic dose after IAT. ${ }^{9}$ Later, since the International Stroke Trial showed that aspirin is superior to heparin for treatment of acute stroke, most patients $(\mathrm{n}=16)$ were given $250-500 \mathrm{mg}$ aspirin after IAT. Some patients were treated with acetazolamide and/or anterior chamber paracentesis before IAT according to the preference of the treating ophthalmologist (table 2).

\section{Conventional treatment group}

In the conventional treatment group $(n=19)$ the patients were treated with aspirin or heparin plus anterior chamber paracentesis and/or acetazolamide or with antithrombotic agents (heparin or aspirin) according to the preference of the treating ophthalmologist (table 2). Clinical and demographic characteristics of the patients are summarised in table 1 .
Table 2 Details of the conventional treatment modalities

\begin{tabular}{|c|c|c|c|}
\hline \multirow[b]{2}{*}{ Treatment } & \multicolumn{2}{|l|}{ Group } & \multirow[b]{2}{*}{ p value* } \\
\hline & $\begin{array}{l}\text { Thrombolysis } \\
(\mathrm{n}=37 \text { ) }\end{array}$ & $\begin{array}{l}\text { Controls } \\
(n=19)\end{array}$ & \\
\hline Acetazolamide & $18(49 \%)$ & $4(21 \%)$ & NS \\
\hline $\begin{array}{l}\text { Anterior chamber } \\
\text { paracentesis }\end{array}$ & $24(65 \%)$ & $4(21 \%)$ & $p=0.004$ \\
\hline Heparin & $21(57 \%)$ & $10(53 \%)$ & NS \\
\hline Aspirin & $16(43 \%)$ & $9(47 \%)$ & NS \\
\hline
\end{tabular}

\section{Visual assessment}

In both groups visual function was assessed by an ophthalmologist using a standardised chart and lighting on admission within 48 hours after treatment and between two and eight weeks (final visual acuity) after treatment. Fluorescein angiography was not routinely used to avoid delays in treatment.

\section{Statistical analysis}

Statistical analysis was carried out with the SPSS 10 for Macintosh software (2001; SPSS Inc.). The Mann-Whitney U test was used to assess pretreatment differences between the thrombolysis and the conventional treatment groups. For analysis of final visual outcome the patients were dichotomised. Visual acuity $>0.6$ was defined as favourable and $\leqslant 0.6$ was defined as minor or poor visual outcome. Final visual acuity between the two groups was compared using Fisher's exact test. Improvement of visual acuity was analysed by the Mann-Whitney test after logarithmic transformation of the non-linear visual scale in a linear scale using the logarithmic minimum angle of resolution (log MAR) scale. For analysing predictors of outcome we considered factors that may have influenced visual outcome in the thrombolysis and the conventionally treated groups separately using non-parametric Spearman's rank correlation or Mann-Whitney tests. For all tests two-sided $\mathrm{p}$ values $<0.05$ were considered significant.

\section{RESULTS}

\section{Demographic and clinical data}

Both groups were well matched for age, sex, vascular risk factors, and aetiology of CRAO (table 1). On ophthalmologic examination, cholesterol emboli were not visualised in all patients. The median (SD) time to treatment was $240 \mathrm{~min}-$ utes (mean $240(62)$ ) in the IAT group and 240 minutes (mean 221 (53)) in the conventional treatment group $(p>0.05)$. Visual acuity before treatment did not differ significantly between the two groups (table 1).

\section{Outcome}

In the IAT group $8 / 37$ patients (22\%) regained visual acuity of $>0.6$ compared with none $(0 / 19)$ in the control group $(p=0.04)$. Improvement of vision was more likely when IAT was performed $(p=0.01)$. Pretreatment and final visual acuity of each patient in both the groups are illustrated in figs 1 and 2. Acetazolamide and/or paracentesis, in addition to antithrombotic treatment, did not improve visual acuity in the IAT group. In the control group vision of patients who received acetazolamide $(n=4)$ was more likely to improve $(\mathrm{p}=0.008)$.

\section{Predictors of outcome}

Younger patients were more likely to regain some vision, both in the IAT $(p=0.012)$ and the control group $(p=0.026)$. When IAT was performed within four hours of the onset of symptoms visual outcome tended to be better than when 


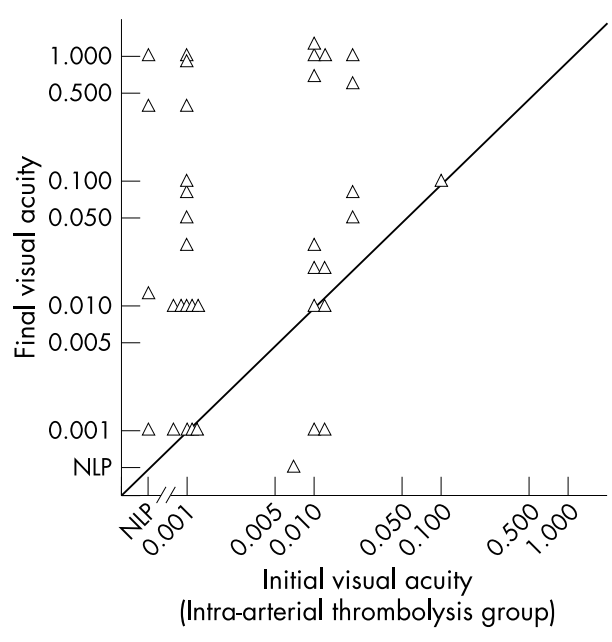

Figure 1 Central retinal artery occlusion: scattergram showing the relation between pretreatment (initial) visual acuity and final visual outcome after intra-arterial thrombolysis $(n=37)$.

patients were treated later $(27 \% v 13 \%$ good outcomes with visual acuity $>0.6 ; \mathrm{p}=0.24$ )

There was no association between sex, vascular risk factors, aetiology of CRAO (local thrombosis, carotid stenosis, cardioembolic) or the mode of antithrombotic treatment (aspirin or heparin) and outcome in both the IAT and control groups.

\section{Adverse events}

Three patients developed periprocedural cerebrovascular ischaemic events, two had transient ischaemic attacks (TIAs) and one a stroke, fortunately without permanent disability. The last was a 55 years old man who experienced sudden right sided hemiparesis during IAT. Cerebral arteriography showed main stem occlusion of the middle cerebral artery that was recanalised immediately with 500000 IE urokinase. His clinical deficits improved rapidly within 30 minutes, but a small striatocapsular stroke was visualised on a post-treatment magnetic resonance imaging (MRI) scan. The patient had no disability follow up at the neurological examination two weeks after treatment. Other adverse events of IAT did not occur, in particular, haemorrhages.

\section{DISCUSSION}

This study compared a group of patients with CRAO, who were treated with IAT within six hours of reduction of vision, and a group of controls, who did not receive IAT but were also seen within six hours of the onset of symptoms. Both groups were well matched for demographic and clinical characteristics (table 1). Visual improvement was more likely with IAT $(p=0.01$; fig 1$)$. In addition, IAT enhanced the chances to regain visual acuity of $>0.6$. In the IAT group $8 / 37$ patients $(22 \%)$ regained visual acuity of $>0.6$ compared with none $(0 / 19)$ in the control group $(p=0.04)$.

Previously published series of patients with CRAO treated with IAT using different thrombolytic agents, inclusion criteria, and time windows reported similar results in favour of IAT. ${ }^{1-3}$

In a recent meta-analysis of 100 patients treated with IAT with a mean time delay of 11.6 hours, $27 \%$ regained visual acuity $\geqslant 0.5 .{ }^{6}$ Despite these promising results, the prognosis of visual outcome remains poor in most of the patients. The questions arising are:

- Which patients should undergo a treatment with potential negative side effects such as intracranial haemorrhage or cerebral ischaemia?

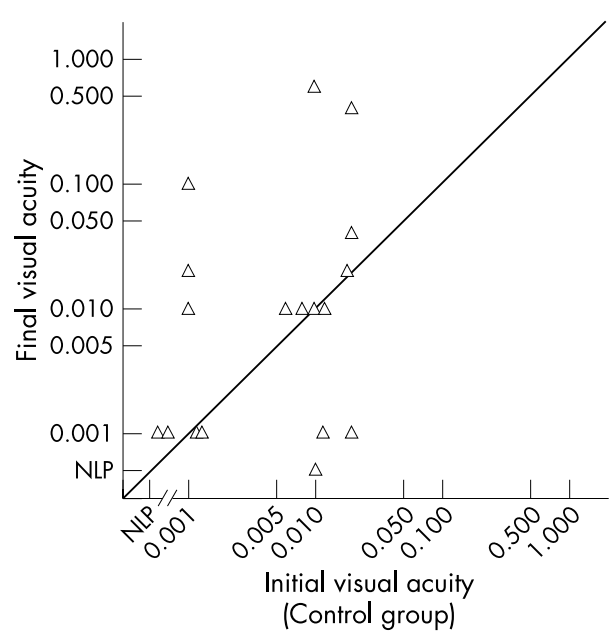

Figure 2 Central retinal artery occlusion: scattergram showing the relation between pretreatment visual acuity and final visual outcome in the control group $(n=19)$.

- Are there patients who may have a spontaneously favourable course?

- Are there patients who should not be exposed to the risks of IAT for CRAO?

Thus, for these reasons we attempted to identify predictors of visual improvement. In this series younger age was the only significant predictor of visual improvement, both in the IAT and in the control group. This observation is consistent with the results of another study of IAT in patients with CRAO and thrombolysis trials of patients with acute stroke. $^{31011}$ However, in this series, and in other studies, some older patients also regained favourable visual acuity after IAT. Therefore, there is no rationale for excluding older patients from treatment solely on the basis of age.

The time interval from the onset of symptoms to treatment did not significantly influence clinical improvement in our patients treated within six hours of symptom onset. However, there was a non-significant trend towards better outcome in patients treated within four hours of the onset of symptoms. Six of the eight patients with final visual acuity $>0.6$ were treated within four hours of symptom onset. This trend may be a chance observation. Results of animal models (rhesus monkeys), however, have shown retinal tolerance of ischaemia up to 100 minutes only, thus it is doubtful that after a few hours many retinal cells can be salvaged by reperfusion. ${ }^{12}$ It is more likely that reperfusion has to be as quick as in stroke. In stroke, there is a clear inverse, exponential correlation of the effect of thrombolysis within the first three hours after symptom onset. ${ }^{13}{ }^{14}$ Some patients with stroke and good collaterals also will benefit from recanalisation after the three hour time limit, but benefit after six hours is exceptional. Since the retina is part of the brain, it is likely that early recanalisation will preserve more retinal cells than late reperfusion.

There was no association between sex, vascular risk factors, aetiology of CRAO, and visual acuity on admission with visual improvement or outcome. Whether a larger sample size would have identified such a correlation remains unanswered. Other authors have not found such an association either. ${ }^{5}$

Patients in the IAT group were more often treated by paracentesis. However, a treatment effect in addition to IAT was not identifiable either for paracentesis or for acetazolamide. In the control group, patients who received acetazolamide $(\mathrm{n}=4)$ were more likely to improve their vision 
$(p=0.005)$. We have to leave open whether this is a meaningful positive result or just a chance observation due to a selection bias. Other authors did not find any effect of acetazolamide or paracentesis. ${ }^{25}$

IAT is an intervention with potentially serious complications including TIA, stroke, and intracerebral or retinal haemorrhage. In a recent meta-analysis the rate of potential serious complications was calculated to be $4 \%{ }^{6}$ In this metaanalysis, all complications were transient; no permanent neurological deficit occurred. We also did not observe any symptomatic intracerebral or retinal haemorrhage. However, despite exclusion of patients with high grade carotid stenosis from the IAT group, two TIAs and one minor ischaemic stroke did occur. In the patient with the minor stroke an embolic middle cerebral artery occlusion was successfully recanalised by IAT. Therefore, in our opinion, it is crucial that IAT in CRAO is performed by a neuroradiologist experienced in IAT of intracerebral vessels as well.

In conclusion, this study indicates that IAT has the potential to improve visual outcome in patients with CRAO compared with conventional treatment. A randomised trial is needed and has already been initiated to confirm the potential benefit of IAT for CRAO and to define the indications and contraindications more precisely.

\section{ACKNOWLEDGEMENT}

We thank Dr Pietro Ballinari for statistical advice.

\section{Authors' affiliations}

M Arnold, K Nedeltchev, H P Mattle, M Sturzenegger, J Weber, Department of Neurology, University of Berne, Berne, Switzerland L Remonda, G Schroth, Department of Neuroradiology, University of Berne, Berne, Switzerland

U Koerner, F Koerner, Department of Ophthalmology, University of Berne, Berne, Switzerland
This study was supported in part by "Stiffung zur Förderung der wissenschaftlichen Forschung an der Universität Bern".

Competing interests: none declared

\section{REFERENCES}

1 Augsburger JJ, Magargal LE. Visual prognosis following treatment of acute central retinal artery obstruction. Br J Ophthalmol 1980;64:913-17.

2 Atebara NH, Brown GC, Cater J. Efficacy of anterior chamber paracentesis and Carbogen in treating acute nonarteritic central retinal artery occlusion. Ophthalmology 1995;102:2029-34.

3 Schmidt D, Schumacher M, Wakhloo AK. Microcatheter urokinase infusion in central retinal artery occlusion. Am J Ophthalmol 1992;113:429-34.

4 Richard G, Lerche RC, Knospe V, et al. Treatment of retinal arterial occlusion with local fibrinolysis using recombinant tissue plasminogen activator. Ophthalmology 1999;106:768-73.

5 Schmidt DP, Schulte-Monting J, Schumacher M. Prognosis of central retinal artery occlusion: local intraarterial fibrinolysis versus conservative treatment AJNR Am J Neuroradiol 2002;23:1301-7.

6 Beatty S, Au Eong KG. Local intra-arterial fibrinolysis for acute occlusion of the central retinal artery: a meta-analysis of the published data. Br J Ophthalmol 2000;84:914-16.

7 Weber J, Remonda L, Mattle HP, et al. Selective intra-arterial fibrinolysis of acute central retinal artery occlusion. Stroke 1998;29:2076-9.

8 Adams HP Jr, Bendixen BH, Kappelle $\sqcup$, et al. Classification of subtype of acute ischemic stroke. Definitions for use in a multicenter clinical trial. TOAST. Trial of Org 10172 in Acute Stroke Treatment. Stroke 1993:24:35-41.

9 The International Stroke Trial (IST). A randomised trial of aspirin, subcutaneous heparin, both, or neither among 19435 patients with acute ischaemic stroke. International Stroke Trial Collaborative Group. Lancet 1997;34:1569-81.

10 Arnold M, Schroth G, Nedeltchev K, et al. Intra-arterial thrombolysis in 100 patients with acute stroke due to middle cerebral artery occlusion. Stroke 2002;33: 1828-33.

11 Ueda T, Sakaki S, Kumon Y, et al. Multivariable analysis of predictive factors related to outcome at 6 months after intra-arterial thrombolysis for acute ischemic stroke. Stroke 1999;30:2360-5.

12 Hayreh SS, Kolder HE, Weingeist TA. Central retinal artery occlusion and retinal tolerance time. Ophthalmology 1980;87:75-8.

13 Marler JR, Tilley BC, Lu M, et al. Early stroke treatment associated with better outcome: the NINDS rt-PA Stroke Study. Neurology 2000;55: 1649-55.

14 Kaste $M$. Approval of alteplase in Europe: will it change stroke management? Lancet Neurol 2003;2:207-8. 